\title{
Space-Time Model to Predict The Evolution of the Regional Subsidence in The Lacustrine Zone of Mexico City
}

\section{Maria Clara Madrigal-Madrigal}

UNAM: Universidad Nacional Autonoma de Mexico

Eduardo Botero-Jaramillo ( $\nabla$ eboj@pumas.iingen.unam.mx )

UNAM: Universidad Nacional Autonoma de Mexico https://orcid.org/0000-0002-3735-4158

Carlos Díaz-Ávalos

UNAM: Universidad Nacional Autonoma de Mexico

\section{Research Article}

Keywords: geostatistic, space-time models, kriging, regional subsidence, $\mathrm{R}$

Posted Date: November 23rd, 2021

DOI: https://doi.org/10.21203/rs.3.rs-1099455/v1

License: (c) (i) This work is licensed under a Creative Commons Attribution 4.0 International License.

Read Full License 


\title{
Space-time model to predict the evolution of the regional subsidence in the lacustrine zone
}

of Mexico City

\author{
Madrigal MC ${ }^{(1)}$, Botero E *(1), Díaz-Ávalos $\mathrm{C}^{(2)}$ \\ Instituto de Ingeniería, Universidad Nacional Autónoma de México (UNAM), Mexico City, Mexico ${ }^{(1)}$ \\ Instituto de Investigaciones en Matemáticas Aplicadas y en Sistemas, Universidad Nacional Autónoma de México \\ (UNAM), Mexico City, Mexico ${ }^{(2)}$
}

\section{Abstract}

In several scientific and engineering disciplines, models have been used to understand the behavior of dynamic processes that evolve in space and in time by providing a probabilistic framework to analyzing the available information. The geostatistical tools used to analyze space-time data are based on established statistical methods, where time is considered as an additional dimension. These models have become very useful in fields such as meteorology, hydrology, ecology, geosciences, and environmental sciences, among others. Subsidence generated by the intense extraction of groundwater in a region is a dynamic phenomenon that manifests itself through the sinking of the ground surface, leading to significant settling in buildings and public utilities as well as cracks in roads. Since the regional subsidence of Mexico City is one of the most representative cases of this type in the world, in this work a model with a full grid space-time layout (STF) is used to analyze and predict the evolution of this phenomenon in the city, taking into account a monitoring system composed of 1931 surface benchmarks. Results show that the separable variogram model was the one that best represented the spatial and temporal correlation of the phenomenon in the area of study. In addition, the differences between the registered ground elevation made in 2016 and those estimated by the space-time model for the same year, were less than $1.00 \mathrm{~m}$. This implies that in general accurate ground elevation values and subsidence rates 
can be obtained from the proposed space-time model during the time period 2010-2030 for the lacustrine zone of Mexico City.

Keywords: geostatistic, space-time models, kriging, regional subsidence, $\mathrm{R}$

*Corresponding author. E-mail address: EBoteroJ@iingen.unam.mx (Botero E)

\section{Introduction}

Most of Mexico City is settled on lacustrine soils in which large amounts of volcanic ash and other pyroclastic materials were deposited (Marsal 1969; Mesri 1975; Romo et al. 1988; Santoyo 2005;

Ovando et al. 2007; Ossa et al. 2019). Over time, chemical degradation of these materials formed clays and clayey silts that are characterized by their high water content, compressibility and low shear strength (Bard et al. 1988; Ovando et al. 2003, 2007, 2013; Ossa et al. 2019). Exploitation of the aquifer underlying these clay deposits began in the mid-19th century to supply water to city's population (Ovando et al. 2003; Santoyo et al. 2005; Ovando et al. 2007). However, the intense exploitation of the aquifers from which an average of $203 \times 10^{6} \mathrm{~m}^{3}$ of water is extracted each year, of which only $156 \times 10^{6} \mathrm{~m}^{3}$ is naturally recharged (Arroyo et al. 2013), has contributed to the induced regional consolidation of lacustrine deposits that is manifested by the lowering of the land surface as voids in the soil are reduced and forces between soil particles increase. The relationship between population growth, the amount of water extracted from the aquifer and subsidence rates in Mexico City was established by Carrillo (1948), and later, by Marsal and Mazari (1959) (Ovando et al. 2013).

From 1900 to 1920 the rate of subsidence in downtown Mexico City was $3 \mathrm{~cm} / \mathrm{year}$, then it increased to $13 \mathrm{~cm} /$ year in the $1940 \mathrm{~s}$ and reached $26 \mathrm{~cm} /$ year in the early $1950 \mathrm{~s}$ (Tamez et al. 
1995; Tamez et al. 1997; Ovando et al. 2007). Then, between 1956 and 1967 the rate of subsidence decreased to $5 \mathrm{~cm} /$ year because extraction of water from the wells in downtown Mexico City was banned (Ovando et al. 2003, 2007; Aguilera 2013). However, in the late 1970s and early 1980s, new wells were put in operation on the outskirts of the city and the rate increased again to $10 \mathrm{~cm} /$ year in downtown Mexico City and at some sites near the new extraction wells, it even exceed 30 cm/year (Mazari 1996; Ovando et al. 2003, 2007, 2013). In the last 100 years, this phenomenon has led to have a cumulative ground subsidence of more than $8 \mathrm{~m}$ in some areas of the lacustrine zone of the Valley of Mexico compared to a reference point outside the lake zone (Ovando et al. 2003, 2013; Arroyo et al. 2013).

The importance of analyzing the behavior of regional subsidence in the lacustrine zone of Mexico City lies in the fact that it can affect the functionality and safety of the city's public services and infrastructure when a significant accumulation of settlements occurs. On the other hand, the drainage system is strongly affected by subsidence because it modifies the gradient, and in some cases, it can cause the inversion of its slope (Lesser and Cortés 1998). In addition, this phenomenon also modifies the static and dynamic properties of the ground, causing a change in the response of the soil deposit during a seismic event. Because of this and given that subsidence in Mexico City is one of the most representative cases of this type in the world, different studies have been carried out to predict the evolution of this phenomenon and mitigate its consequences.

In 1976, the General Directorate of Construction and Hydraulic Operation (DGCOH, in Spanish) of the Federal District government began the installation of surface benchmarks (topographic references whose elevation and location coordinates are known) to understand the behavior of regional subsidence over time, provide solutions to the problems of hydraulic systems in the Valley of Mexico and assist in the design of future projects (SIMOH 2015). As a result of 
this work, the evolution of the benchmarks in the time period 1984-2002 and a map with the cumulative subsidence of the entire area of Mexico City are presented in the Integrated Water Resources Management Program (SACMEX 2005). Lesser and Cortés (1998) prepared a historical analysis and simulated subsidence along the 17 main drainages of Mexico City, including the Grand Canal and the Churubusco River, among others, using a linear statistical method, a logarithmic regression and the application of a mathematical model developed by Cruickshank et al. (1979).

While some studies focused on measuring the ground subsidence for several sites in Mexico City, others were developed to analyze the effects of this phenomenon on the static and dynamic properties of lacustrine deposits and on its seismic response during a seismic event. Jaime (1988) identified that the water content, strength, compressibility, and dynamic properties of the soil underlying Mexico City are time-dependent because of water extraction (Arroyo et al. 2013). The works of Ovando et al. (2003, 2007, 2013) were based on the model of Yin and Graham (1994, 1996) to propose expressions to determine the deformations generated during one-dimensional consolidation process in the soil mass. On the other hand, Avilés and Pérez-Rocha (2010) proposed an empirical model that extrapolates historical data of the elevations of the metropolitan area of Mexico City obtained from benchmarks, to evaluate and predict the evolution of the natural period of soil vibration $\mathrm{T}_{\mathrm{s}}$ and the depth of Deep Deposits between the years 2005 and 2055. In addition, Arroyo et al. (2013) presented field evidence about the effect of the subsidence phenomenon on the natural period of soil vibration $\mathrm{T}_{\mathrm{s}}$ and developed an empirical model to predict the value of this parameter at different sites in Mexico City for the years 2010 and 2050.

Hence, it can be evidenced that there is no a specific theoretical or empirical method to analyze the subsidence phenomenon in the lacustrine area of Mexico City, since it is a complex process in 
which there is an interaction between hydraulic and geotechnical factors. The purpose of this work is to predict the behavior in space and time of the surface benchmarks located in the Lake zone of Mexico City, and to analyze the evolution of the regional subsidence phenomenon from a statistical point of view by using a space-time model.

\section{Space-time data analysis methods}

Geostatistics refers to the analysis of the possible observations of a random phenomenon of interest $\{Z(s): s \in \mathcal{D}\}$ that is defined at all points in a study region $\left\{\mathcal{D} \subset \mathbb{R}^{d}\right\}$. One of the purposes of geostatistics is to make predictions of the variable of interest $Z(s)$ at unvisited locations $s_{0}$. In general, geostatistical analysis consists of the following four stages: exploratory analysis, structural analysis, spatial modeling, and estimations and predictions.

The geostatistical tools used to analyze space-time data are based on established spatial techniques, where time is considered as an additional spatial dimension.

In the spacetime package of the R statistical program (R Core Team 1993; RStudio Team 2015) four grid formats for spatiotemporal data are included, but in this work the full grid spacetime layout (STF) is used. This grid represents a combination of spatial $s_{i}, i=1, \ldots, n$ and temporal $t_{j}, j=1, \ldots, m$ attributes for a total of $z_{k}$ stored observations, with $k=1, \ldots, n m$, which represent all possible locations in the spatiotemporal grid of the phenomenon of interest (Fig. 1).

Fig.1 Full grid layout (modified from Pebesma 2012)

\section{Spatio-temporal models}

Consider a spatio-temporal random field $Z$ defined in a spatial domain $S$ and a temporal domain $T$, for which there is a sample $z=\left\{z\left(s_{1}, t_{1}\right), \ldots, z\left(s_{n}, t_{n}\right)\right\}$ of observations at known locations $\left\{\left(s_{1}, t_{1}\right), \ldots,\left(s_{n}, t_{n}\right) \in S \times T \subseteq \mathbb{R}^{2} \times \mathbb{R}\right\}$ (Gräler et al. 2016). To perform estimations and predictions of the random variable $Z$ at unobserved locations, the sample $z$ data are considered. For this purpose, 
the random field $Z$ is assumed to be stationary and spatially isotropic, so it can be characterized through the mean $\mu$ and a covariance function $C_{s t}$, which for two points $(s, t),(s+h, t+u)$ depends only on the separating distances across space $h \in \mathbb{R}^{2} \geq 0$ and time $u \in \mathbb{R} \geq 0$. The spatio-temporal covariance function is given by $C_{s t}=\operatorname{Cov}(Z(s, t), Z(\tilde{s}, \tilde{t}))$ where $h=\|s-\tilde{s}\|$ and $u=\|t-\tilde{t}\|$ are the spatial and temporal distances of a pair of points $(s, t),(\tilde{s}, \tilde{t}) \epsilon S \times T$. In general, the spatio-temporal variograms $\gamma_{s t}(h, u)=C_{s t}(0,0)-C_{s t}(s, t)$ are most often used to characterize a random phenomenon $Z$, since it is not required to estimate the mean of $Z$ to calculate this function (Gräler et al., 2016). The variogram models implemented in the $\mathrm{R}$ gstat package make it possible to relate objects to spatiotemporal characteristics and to estimate and predict these in space and time.

The separable variogram model (Eq.1) has a great computational advantage when each spatial object has an observation at each temporal instance, i.e., when the data are organized in a full grid layout (Pebesma 2012). On the other hand, it is the simplest form of spatio-temporal models where the dependence of the spatial coordinates is separated from the dependence of the temporal coordinates (De Iaco et al. 2011).

$$
\gamma_{\text {sep }}(h, u)=\operatorname{sill} \cdot\left(\bar{\gamma}_{s}(h)+\bar{\gamma}_{t}(u)-\bar{\gamma}_{s}(h) \bar{\gamma}_{t}(u)\right)
$$

where, $\bar{\gamma}_{s}(h)$ and $\bar{\gamma}_{t}(u)$ are the standardized spatial and temporal variograms, respectively. The above model extends to the product - sum variogram model (Eq.2) developed by De Cesare et al. (2001) and De Iaco et al. (2001) where, unlike the previous one, they considered nonseparable variograms to represent the spatiotemporal variability of the data.

$$
\gamma_{p s}(h, u)=\left(k \cdot \operatorname{sill}_{\mathrm{t}}+1\right) \gamma_{s}(h)+\left(k \cdot \operatorname{sill}_{\mathrm{s}}+1\right) \gamma_{t}(u)-k \gamma_{s}(h) \gamma_{t}(u)
$$


where, $\gamma_{s}(h)$ and $\gamma_{t}(u)$ are the spatial and temporal variograms, respectively, and $k$ is a

136 positive parameter that defines the joint sill (Eq.3), sill st $_{\text {, in terms of the spatial sill }}$ and temporal

$137 \operatorname{sill}_{\mathrm{t}}$.

$$
\operatorname{sill}_{\mathrm{st}}=k \cdot \operatorname{sill}_{\mathrm{s}} \cdot \operatorname{sill}_{\mathrm{t}}+\operatorname{sill}_{\mathrm{s}}+\operatorname{sill}_{\mathrm{t}}
$$

Bilonick (1988) proposed the sum - metric model (Eq. 4), an extension of the separable variogram model, using zonal and geometric anisotropy to resolve the differences between spatial and temporal variability (Snepvangers et al. 2003).

$$
\gamma_{s m}(h, u)=\gamma_{s}(h)+\gamma_{t}(u)+\gamma_{\text {joint }}\left(\sqrt{h^{2}+(k \cdot u)^{2}}\right)
$$

where, $\gamma_{s}(h), \gamma_{t}(u)$ and $\gamma_{\text {joint }}$ are the spatial, temporal, joint variograms, respectively, and $k$ is the anisotropy.

\section{Spatio-temporal analysis of the regional subsidence in Mexico City.}

\subsection{Description of the database}

The General Directorate of Hydraulic Construction and Operation (DGCOH) of the Federal District government, today Mexico City Water Bureau (SACMEX, in Spanish), began in 1976 the installation of surface benchmarks to understand the evolution of subsidence and to provide solutions to the problems of hydraulic systems in the Valley of Mexico (SIMOH 2015).

The monitoring system consists of 1931 surface benchmarks monitored during the period 1983-2016 with readings every two years, approximately. These benchmarks have as reference point the Atzacoalco benchmark, which is located at an elevation of 2245.008 meters above sea level (masl) fixed on the rocky body of the Sierra de Guadalupe, outside the lacustrine zone (SIMOH 2015).

To build the database, perform the statistical analysis and develop a spatial-temporal model, the information provided was reviewed and only those benchmarks located in the Lake zone 
(Zone III) (Fig. 2) of Mexico City were considered. In addition, those that presented at most two missing records in non-consecutive years were also included in order to have a full space-time grid layout (STF) of observations, where each spatial point $s_{i}, i=1, \ldots, n$, has a measurement in each one of the monitoring years $t_{j}, j=1, \ldots, m$ (Fig. 1). Once these benchmarks were selected, those that showed erratic behavior during the monitoring time, i.e., that instead of showing a decrease in the elevation records due to the sinking ground surface, they showed an increase, were eliminated. In the end of this data review, 206 spatial features remained, each with thirteen time points $(1983,1985,1987,1989,1992,1994,1996,1998,2000,2002,2005,2007,2016)$ for a total of 33 years of monitoring. Fig.2 shows the location of these benchmarks. The minimum distance between them is $112.25 \mathrm{~m}$ and the maximum distance is $2,131.32 \mathrm{~m}$.

Fig.2 Benchmarks included in the analysis

It should be noted that the time points of the year 2016 were not considered in the space-time analysis, since they were used to validate the predictions made with the model obtained.

Fig. 3 shows the ground elevations measurements recorded in masl for each year of observation at the points where the benchmarks are located. In addition, Fig. 4 shows the gradual sinking of the lacustrine zone registered at these topographic references over 24 years of monitoring. In this figure, it can be seen that this phenomenon shows a trend over time, so it is a non-stationary process.

Fig.3 Ground elevations (masl) between the time period 1983-2007

Fig.4 Evolution of the ground elevations between the time period 1983-2007

Based on the ground elevations and the time interval differences between records, the mean rate of subsidence in centimeters per year (cm/year) was determined for each benchmark. The highest mean rate was $35.11 \mathrm{~cm} /$ year, which was recorded in a benchmark located in the Iztapalapa 
locality of Mexico City, where a maximum cumulative subsidence of $8.41 \mathrm{~m}$ occurred during this time period. Then, to estimate the spatial distribution of the subsidence rates in the Lake zone, a kriging interpolation was performed using a 100 x 100 m grid (Fig.5)

Fig.5 Mean subsidence rates for the time period 1983-2007

\subsection{Structural analysis}

To determine the behavior of an attribute of interest $z=\{z(s, t) \mid s \in S, t \in T\}$ defined in a geographic domain $S \subset \mathbb{R}^{2}$ and a time interval $T \subset \mathbb{R}$, at a spatiotemporal point $\left(s_{0}, t_{0}\right)$ where $\mathrm{z}$ was not measured, the observations of the phenomenon $Z$ at points $\left(s_{i}, t_{i}\right)$ are taken into account. To predict $z\left(s_{0}, t_{0}\right)$ it is assumed that $\mathrm{z}$ is a spatiotemporal realization of the random process $Z$, so it is required to characterize, both spatially and temporally, the variability of the phenomenon to predict $Z\left(s_{0}, t_{0}\right)$.

The spatiotemporal random process $Z$ is composed of two functions (Eq. 5), a deterministic one that represents the mean behavior of the phenomenon $(m)$ and a stochastic residual $(\epsilon)$ one.

$$
Z\left(s_{i}, t_{i}\right)=m\left(s_{i}, t_{i}\right)+\epsilon\left(s_{i}, t_{i}\right)
$$

Since the regional subsidence phenomenon is not a stationary process as it presents a trend over time, the spatiotemporal variogram $\gamma\left(s_{i}, s_{j}, t_{i}, t_{j}\right)$ was determined from the stochastic residual function $\epsilon$ of the random process as follows:

$$
\gamma\left(s_{i}, s_{j}, t_{i}, t_{j}\right)=\frac{1}{2} E\left[\left(\epsilon\left(s_{i}, t_{i}\right)-\epsilon\left(s_{j}, t_{j}\right)\right)^{2}\right]
$$

Under the assumptions of stationarity, an estimate of the spatiotemporal variogram, $S T$, can be obtained by calculating the empirical semivariogram $\hat{\gamma}\left(h_{S}, h_{T}\right)$ from the observations as it is shown in Eq. 7.

$$
\hat{\gamma}\left(h_{S}, h_{T}\right)=\frac{1}{2 N\left(h_{S}, h_{T}\right)} \sum_{i=1}^{N\left(h_{S}, h_{T}\right)}\left[\left(\epsilon(s, t)-\epsilon\left(s+h_{S}, t+h_{T}\right)\right)^{2}\right]
$$


where, $h_{S}$ and $h_{T}$ are the distances in space $S$ and time $T$, respectively, and $N\left(h_{S}, h_{T}\right)$ corresponds to the number of pairs.

Figure 6 shows the empirical spatiotemporal semivariogram of the behavior of the benchmarks located in the lacustrine zone of Mexico City (Zone III of Fig. 2). In addition, to observe the differences between the semivariances in the spatial direction $S$ and temporal direction T, marginal semivariograms were also obtained (Fig. 7).

Fig.6 Empirical spatiotemporal semivariogram

Fig.7 Empirical marginal temporal (left) $T: \gamma\left(0, h_{T}\right)$ and spatial (right) $S: \gamma\left(h_{S}, 0\right)$

semivariograms

Finally, the pooled variogram $\gamma(\tilde{h})$ where the spatial correlation of the residual $\epsilon$ is considered constant over time was also determined as follows:

$$
\gamma(\tilde{h})=\frac{1}{2 \sum_{i=1}^{12} N\left(h_{S}\right)} \sum_{i=1}^{12} \sum_{j=1}^{N\left(h_{S}\right)}\left[\left(\epsilon(s, t)-\epsilon\left(s+h_{S}, t\right)\right)^{2}\right]
$$

where, $i=1, \ldots, 12$ correspond to the monitoring years and $N\left(h_{S}\right)$ are the number of pairs of points that are separated by a distance $\tilde{h}$ in year $t$. Fig. 8 shows the pooled variogram and the adjusted Gaussian model that has a nugget of 1.25 , a range equal to $5725.92 \mathrm{~m}$ and a sill equal to

\subsection{7.}

Fig.8 Pooled variogram

\subsection{Fitting variogram models}

The parameters of the functions fitted to the marginals and pooled data semivariograms were considered as initial values to fit the separable, product-sum and sum-metric variogram models using the R gstat package (Eq. (1), (2) and (4)). Fig. 9 shows the empirical spatiotemporal semivariogram of the phenomenon and the fitted models. 


\section{5}

Fig.9 Empirical spatiotemporal semivariograma of the regional subsidence in Mexico City lacustrine area between the time period 1983-2007(upper left corner) and fitted models: separable, product-sum and sum-metric

To assess the goodness of the fit of the models and the empirical semivariogram, the rootmean-square-deviation (RMSD) was determined between the surfaces (Table 1).

Table 1. Root mean square deviation

\begin{tabular}{|c|c|}
\hline Model & RMSD \\
\hline Separable & 0.0645 \\
\hline Product-sum & 0.0663 \\
\hline Sum-metric & 0.0819 \\
\hline
\end{tabular}

Table 1 shows that the separable model characterizes adequately the behavior of the data by having the lowest value of the RMSD. Fig. 10 presents the Gaussian functions fitted to the marginal experimental semivariograms obtained from the separable model.

Fig.10 Separable model fitted to the empirical marginal temporal $T$ (left) and spatial $S$ (right) semivariograms

After fitting a theoretical model to the empirical semivariogram, predictions of the phenomenon in space and time are made by kriging.

\subsection{Predictions}

To estimate the evolution of the regional subsidence phenomenon in Mexico City, a standard kriging was performed up to the year 2030, considering the benchmark locations as estimation points. The results obtained are shown in Fig. 11. For the year 2030, a maximum cumulative subsidence of $13.16 \mathrm{~m}$ was predicted in benchmark B(N01E06)02 with $\mathrm{X}$ and $\mathrm{Y}$ coordinates 494937.29 and 2149738.37, respectively, near the Mexico City International Airport. 
Fig.11 Evolution of the ground elevations during the time period 1983-2030 at the points

where the benchmarks are located

Once the ground elevation values were determined for each of the benchmarks for the period 2010-2030, the mean subsidence rates were calculated in centimeters per year, and a standard kriging interpolation was performed on a 100 m x 100 m grid considering a Gaussian variogram model with nugget 10, sill 60 and range $6000 \mathrm{~m}$ (Fig. 12)

Fig.12 Semivariogram of the predicted mean subsidence rate in the time period 2010-2030

Fig. 13 shows the subsidence rate map for the time-period 2010-2030. The highest mean rate was $25.06 \mathrm{~cm} /$ year, which was recorded in benchmark $\mathrm{B}(\mathrm{N} 01 \mathrm{E} 06) 02$ where the maximum cumulative subsidence for the year 2030 is presented. Comparing this figure with Fig. 5, which shows the subsidence rate map for the time-period 1983-2007, it can be observed that the rate slows by approximately $30 \%$, which is consistent with the behavior of the phenomenon.

Fig.13 Mean subsidence rate in the time period 2010-2030

\subsection{Validation of the predictions}

The validation process consisted of comparing the direct measurements made in the year 2016 in the benchmarks with the ground elevations obtained from the model for the same year. This process was made to verify that the predicted values from the space-time model represent physically the behavior of regional subsidence in Mexico City.

Eq. 9 was used to determine the error, $\varepsilon$, between the registered ground elevations and those estimated by the space-time model.

$$
\varepsilon=\text { measured value }- \text { predicted value }
$$

Fig. 14 shows the box-plot of the errors in meters where it can be observed that they have little variability $\left(\sigma^{2}=0.21\right)$, a mean equal to $0.08 \mathrm{~m}$ and a few outliers. 
Fig.14 Box-plot of the errors in meters

In addition, Fig. 15 shows the spatial distribution of these errors in absolute values. In this figure it can be seen that at $99 \%$ of the sites the differences between the measured and predicted value are less than $1.00 \mathrm{~m}$. This implies that in general accurate ground elevation values and subsidence rates can be obtained from the proposed space-time model during the time period 20102030 for the lacustrine zone of Mexico City.

Fig.15 Distribution of the absolute errors in meters

\section{Discussion}

A statistical method was developed for spatiotemporal modeling of the regional subsidence in Mexico City. In this case, the results obtained from the analysis using a full grid layout are considered as a first approximation of the behavior of the superficial benchmarks for the time period 2010-2030. However, an improvement of the model could be made by considering a sparse grid layout to include more valuable spatial information.

The predictions were made until 2030 because the results obtained at the sites where the benchmarks are located showed that the phenomenon would follow a constant behavior implying that this consolidation process will eventually stop, which is incorrect. The subsidence rates decrease over time because the main clay substrata lose compressibility, gain strength and become stiffer; however, it is impossible to stablish a specific time instant in which this phenomenon ends due to this process follows an asymptotic behavior over time.

In this case, the benchmark locations were considered as estimation points to predict the evolution of the regional subsidence in Mexico City because the validation process consisted of comparing the direct measurements made at these sites with the ground elevations obtained from 
283 the model. Nevertheless, another validation process could be made by comparing the results with

284 a digital elevation model available for the region.

\section{6. Conclusions}

286 This paper presented a statistical interpretation of the behavior of a monitoring system composed

287 of surface level benchmarks installed by the General Directorate of Hydraulic Construction and 288 Operation $(\mathrm{DGCOH})$ in Mexico City, to predict the regional subsidence evolution in the lake area 289 where most of the city is located. For this purpose, the information composed of a network of 1931 290 benchmarks monitored during the time period 1983-2016 provided by the Mexico City Water 291 Bureau (SACMEX) was reviewed. In this review process, those topographic references that were 292 not located in the lacustrine zone, that did not have a reliable behavior during the monitoring time 293 and that presented more than two missing records in consecutive years were discarded. In the end, 294206 of the 1931 benchmarks were considered in the space-time geostatistical analysis each with 295 twelve time points.

296 A full space-time grid of observations was considered in the space-time analysis and the 297 empirical and the marginal semivariograms were determined from the data in terms of their 298 residuals. Theoretical models available in the $\mathrm{R}$ gstat package were fitted to these semivariograms 299 and the numerical criterion to determine the goodness of the fitting was to calculate the root-mean300 square-deviation (RMSD) between the empirical and theoretical surfaces.

301 Based on the RMSD value, the separable model was the one that best represented the spatial 302 and temporal correlation of the observations of the phenomenon in the area of study, so it was 303 considered to perform a spatio-temporal kriging to predict the ground level values during the time 304 period 2010-2030 at the sites where the 206 benchmarks are located. 
Once the corresponding estimates and predictions were made, the mean subsidence rates were calculated and compared with those determined for the time period 1983-2007. From the above, it was observed that there was a decrease of $30 \%$ in the mean subsidence rate which is consistent with the behavior of the phenomenon.

The validation process of the predictions consisted of comparing the direct measurements made in the year 2016 in the benchmarks with the ground elevations obtained from the model for this same year. It was observed that in $99 \%$ locations points, differences were less than $1.00 \mathrm{~m}$ and they had little variability $\left(\sigma^{2}=0.21\right)$ around the mean $(\mu=0.08 \mathrm{~m})$.From the above, it can be concluded that the proposed spatiotemporal model adequately represents the behavior of regional subsidence in space and time in Mexico City, and that it could be considered as another approximation to estimate its evolution in the lacustrine area.

In a next stage of this work, the ground measurements obtained from this space-time model would be used to determine the changes in the seismic response of the clay deposits caused by this phenomenon. This would provide information about the earthquake-resistant design that the structures located in the lacustrine area should have to ensure a satisfactory performance during a seismic event.

\section{References}

Aguilera P (2013) Catedral Metropolitana: hundimiento y rescate. Chapter II. Universidad Nacional Autónoma de México. Instituto de Ingeniería. Mexico

Arroyo D, Ordaz M, Ovando-Shelley E, Guasch JC, Lermo J, Pérez C, Alcántara L, RamírezCenteno MS (2013) Evaluation of the change in dominant periods in the lake-bed zone of 
Mexico City produced by ground subsidence through the use of site amplification factors. Soil Dynamics and Earthquake Engineering (44):54-66.

Avilés J, Pérez-Rocha L (2010) Regional subsidence of Mexico City and its effects on seismic response. Soil Dynamics and Earthquake Engineering (44):54-66.

Bard PY, Campillo M, Chávez-García FJ, Sanchez-Sesma F (1988) The Mexico Earthquake of September 19, 1985: A theoretical investigation of large and small scale amplification effects in the Mexico City Valley. Earthquake Spectra (4):609-633.

Bilonick RA (1988) Monthly hydrogen ion deposition maps for the northeastern U.S. from july 1982 to september 1984. Atmospheric Environment (22) 9:1909-1924.

Bivand RS, Pebesma E, Gómez-Rubio V (2013) Applied Spatial Data Analysis with R. Second Edition, Springer New York Heidelberg Dordrecht, London.

Carrillo N (1948) Influence of artesian wells in the sinking of Mexico City. Proceedings of the IIth Congress of International Soil Mechanics and Foundation Engineering, Rotterdam, Vol. 6, 156-159.

Cruickshank C, Herrera I, Yates R, Hennart JP, Balarezo D, Magaña del Toro R (1979) Modelo de predicción del hundimiento del subsuelo del Valle de México. Instituto de Ingeniería, UNAM. Elaborado para el Departamento del Distrito Federal, México.

De Cesare L, Myers D, Posa D (2001) Estimating and modeling space-time correlation structures. Statistics and Probability Letters (51) 1:9-14.

De Iaco S, Myers D, Posa D (2001) Space-time analysis using a general product-sum model. Statistics and Probability Letters (51) 1:9-14.

De Iaco S, Myers D, Posa D (2011) One strict positive definiteness of product and product-sum covariance models. Journal of Statistical Planning and Inference (141):1132-1140 
Gräler B, Pebesma E, Heuvelink G (2016) Spatio-Temporal Interpolation using gstat. The R Journal (8)1: 204-2018.

Jaime A (1988) Geotecnia y Sismicidad en el Valle de México. Reporte No. D. Serie Azul, Instituto de Ingeniería, UNAM. Mexico

Lesser JM, Cortés M (1998) El hundimiento del terreno en la ciudad de México y sus implicaciones en el sistema de drenaje. Ingeniería Hidráulica en México 3(13):13-18.

Marsal R J, Mazari M (1959) The Subsoil of Mexico City. Escuela de Ingeniería. Universidad Nacional Autónoma de México. Mexico

Marsal RJ, Graue R (1969) El subsuelo del lago de Texcoco. Nabor Carrillo Conmemorative Volume: $167-202$.

Marsal M (1996) La isla de los perros, México: El Colegio Nacional.

Mesri G, Rohsar B, Bohor BF (1975) Composition and compressibility of typical samples of Mexico City clay. Geotechnique (25): 527-554

Ossa A, Romo MP (2007) The sinking of Mexico City: Its effects on soil properties and seismic response. Soil Dynamics and Earthquake Engineering (44):54-66.

Ossa A, Botero E, Madrigal MC, Ovando E, Mendoza M, López-Acosta NP (2019) Performance of a pavement foundation system based on the partial compensation of masses method. Soils and Foundations (59):351-366.

Ovando E, Romo MP, Contreras N, Giralt A (2003) Effects on soil properties of future settlements in downtown Mexico City due to ground water extraction. Geofísica Internacional 42(2):185-204.

Ovando E, Ossa A, Romo MP (2007) The sinking of Mexico City: Its effects on soil properties and seismic response. Soil Dynamics and Earthquake Engineering 27 (4):333-343. 
Ovando E, Ossa A, Santoyo E (2013) Effects of regional subsidence and earthquakes on arquitectural monuments in Mexico City. Boletín de la Sociedad Geológica Mexicana $65(1): 157-167$.

Pebesma E (2012) spacetime: Spatio-Temporal Data in R. Journal of Statistical Software (51)7.

R Core Team (1993) R: A Language and Environment for Statistical Computing. R Foundation for Statistical Computing, Vienna, Austria. ( http://www.R-project.org/).

Romo MP, Jaime A, Reséndiz D (1988) Mexico earthquake of September 19, 1985: General soil conditions and clay properties in the Valley of Mexico. Earthquake Spectra (4): 731-752.

RStudio Team (2015) RStudio: Integrated Development for R. RStudio, Inc., Boston, MA. (http://www.rstudio.com/).

SACMEX (2005) Programa de Gestión Integral de los Recursos Hídricos. Sistema de Aguas de la Ciudad de México. Administración Pública del Distrito Federal. Gobierno del Distrito Federal. Décima Quinta Época. 27 de mayo de 2005. No.62-BIS

Santoyo-Villa E, Ovando-Shelley E, Mooser F, León Plata E (2005) Síntesis Geotécnica de la Cuenca del Valle de México. México D.F.: TGC.

SIMOH (2015) Sistema de Monitoreo de la Piezometría y de los Hundimientos del Valle de México por Extracción de Agua Subterránea. Informe Final elaborado para la Comisión Nacional del Agua (CONAGUA). Convenio: CGPEAYS-UNAM-04/2013. Instituto de Ingeniería de la UNAM.

Snepvangers J, Heuvelink G, Huisman J (2003) Soil water content interpolation using spatio temporal kriging with external drift. Geoderma (112):253-271.

Tamez E, Santoyo E, Cuevas A, Ovando-Shelley E (1995). Diagnóstico y proyecto geotécnico. Chapter II. In: Catedral Metropolitana: corrección geométrica, informe técnico. Mexico 
City: Asociación de Amigos de la Catedral Metropolitana de México, A.C, Zaldívar, S., 41114.

398 Tamez E, Ovando-Shelley E, Santoyo E (1997) Underexcavation of the Metropolitan Catedral in 399 Mexico City. Proceedings of the XIVth International Conference on Soil Mechanics and $400 \quad$ Foundation Engineering, Special Invited Lecture, Hamburg, Vol.4, 2105-2126.

401 Yin JH, Graham J (1994) Equivalent times and one dimensional elastic viscoplastic modelling of 402 time dependent stress-strain behavior of clays. Canadian Geotechnical Journal 31 (1):42-52.

403 Yin JH, Graham J (1996) Modelling of one-dimensional consolidation. Geotechnique 46 (3):515404 527. 
Figures

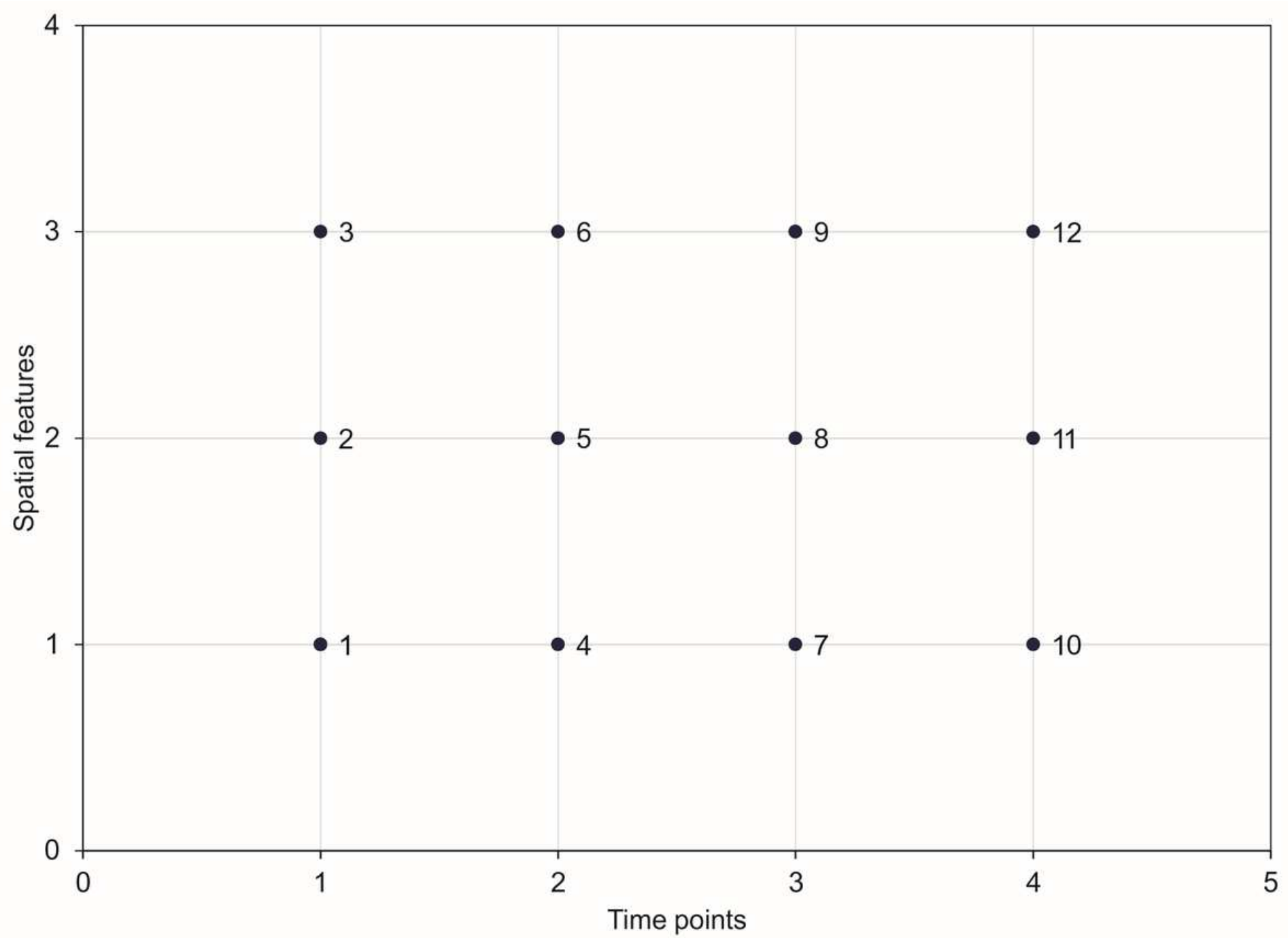

Figure 1

Full grid layout (modified from Pebesma 2012)

展

Figure 2

Benchmarks included in the analysis 


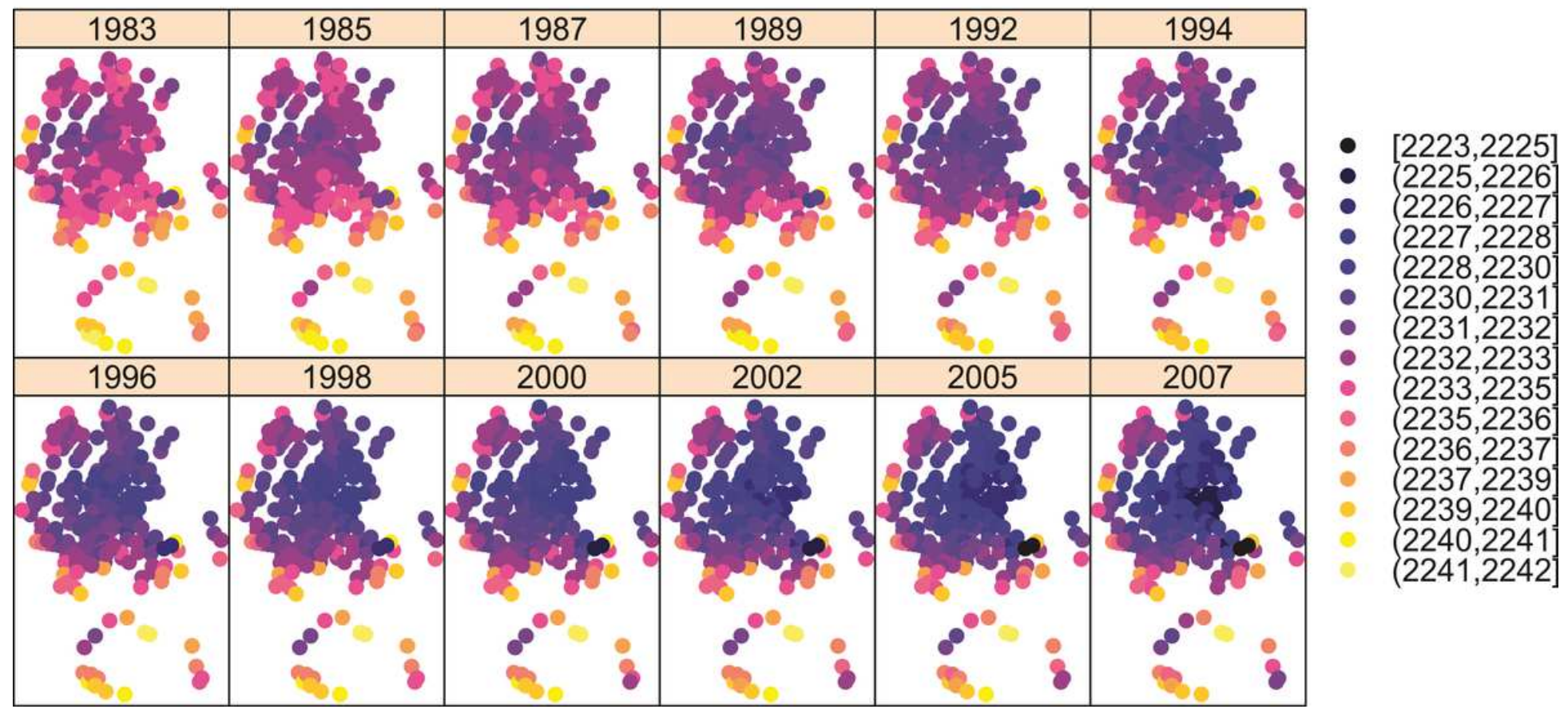

Figure 3

Ground elevations (masl) between the time period 1983-2007

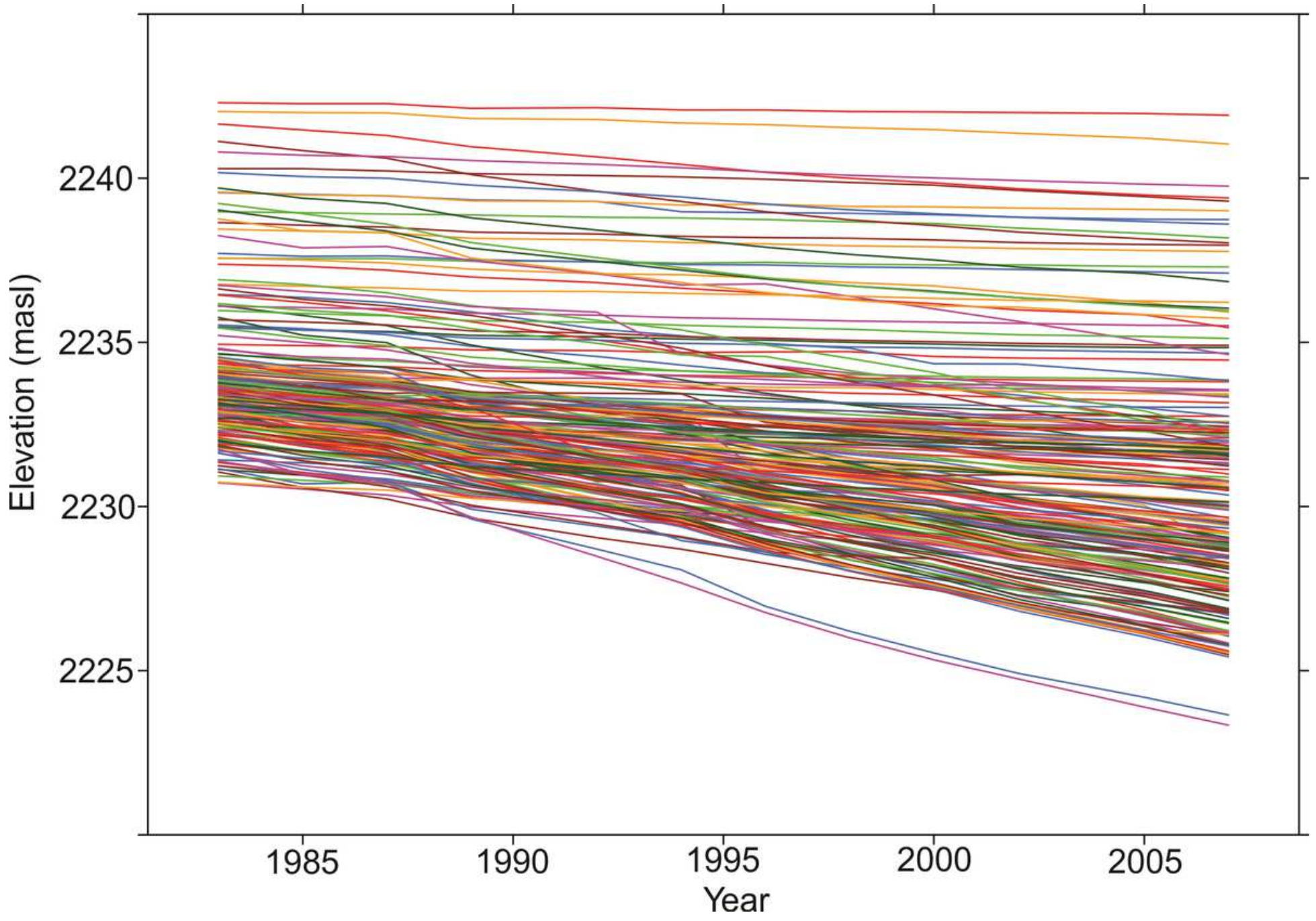


Figure 4

Evolution of the ground elevations between the time period 1983-2007

Figure 5

Mean subsidence rates for the time period 1983-2007
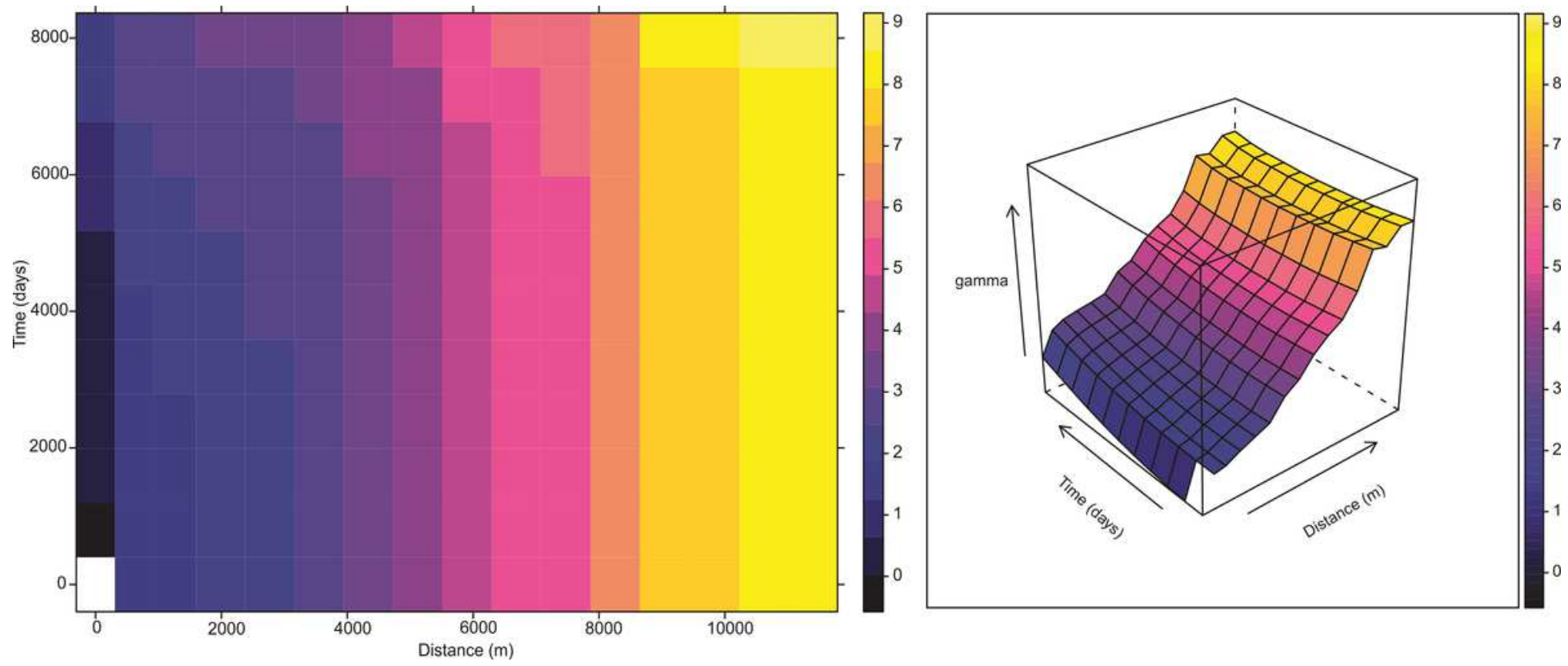

Figure 6

Empirical spatiotemporal semivariogram
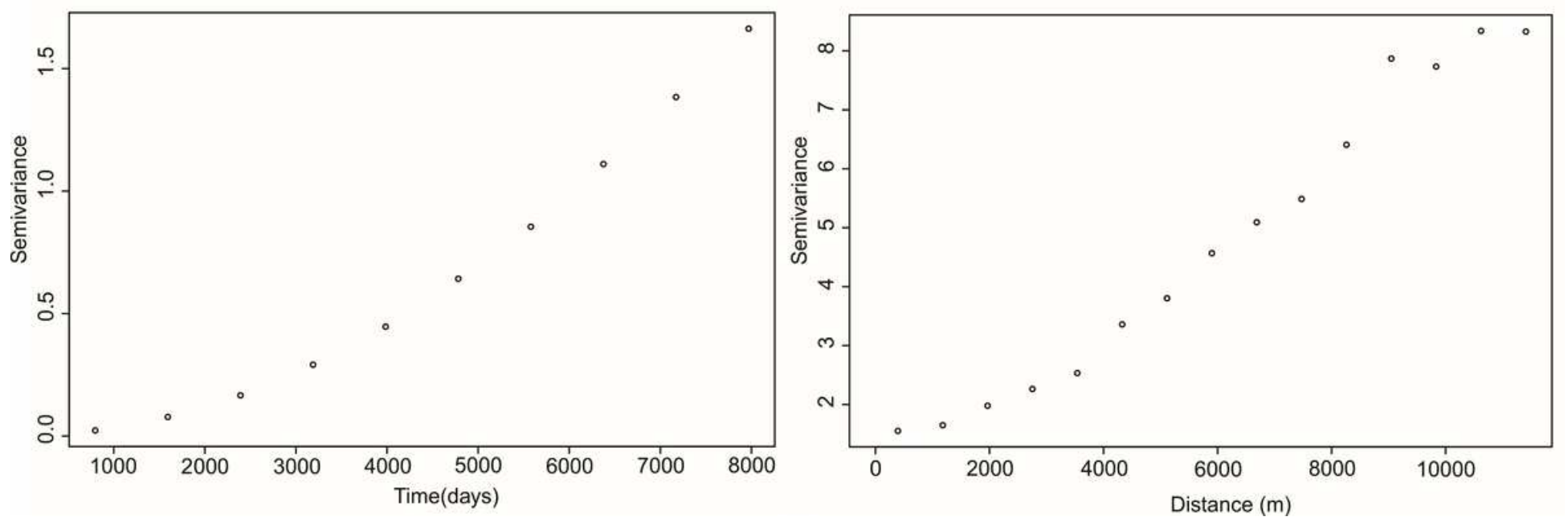

Figure 7

Empirical marginal temporal (left) $T: \gamma\left(0, h_{-} T\right)$ and spatial (right) $S: \gamma\left(h \_S, 0\right)$ semivariograms 


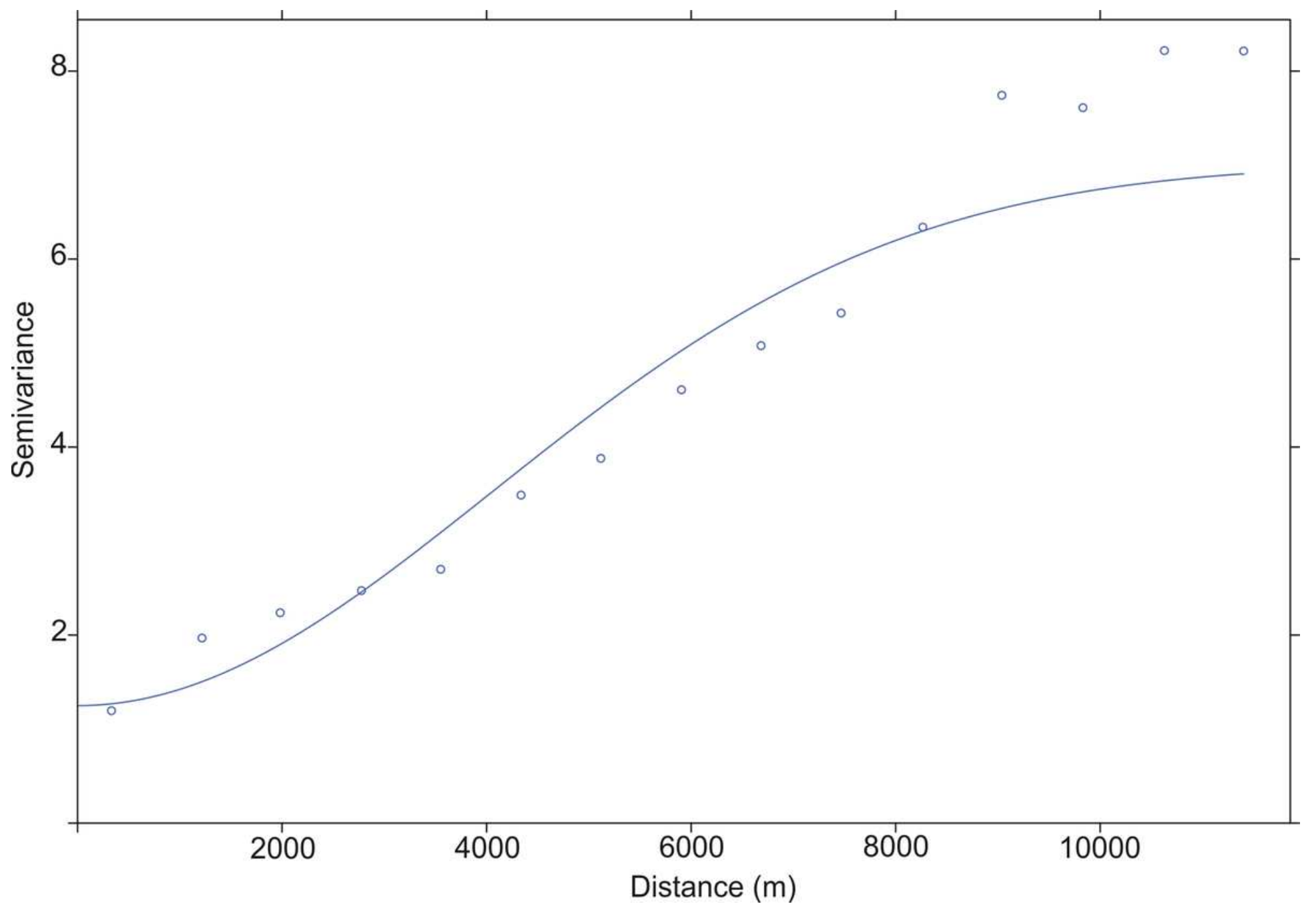

Figure 8

Pooled variogram 

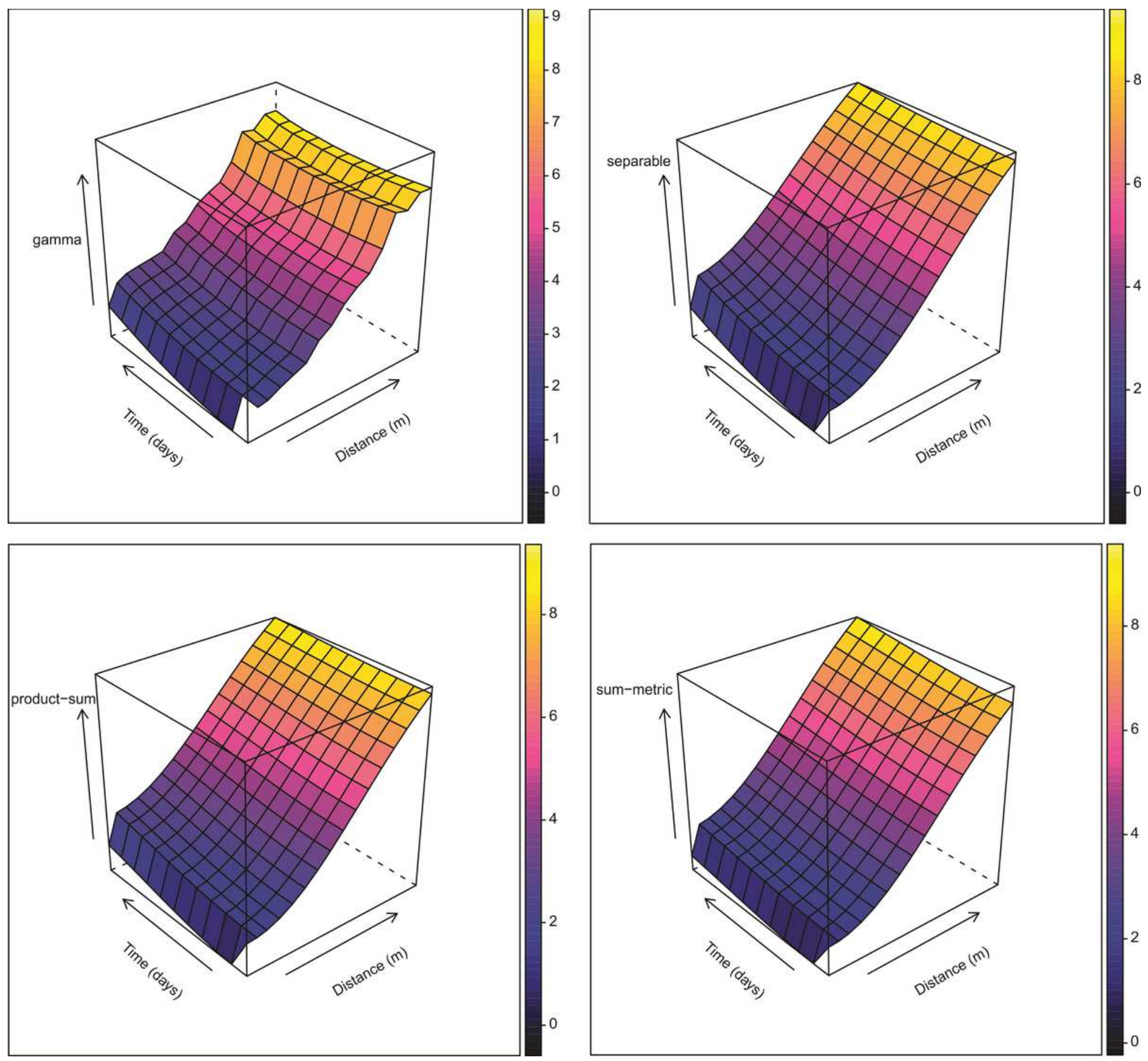

Figure 9

Empirical spatiotemporal semivariograma of the regional subsidence in Mexico City lacustrine area between the time period 1983-2007(upper left corner) and fitted models: separable, product-sum and sum-metric 

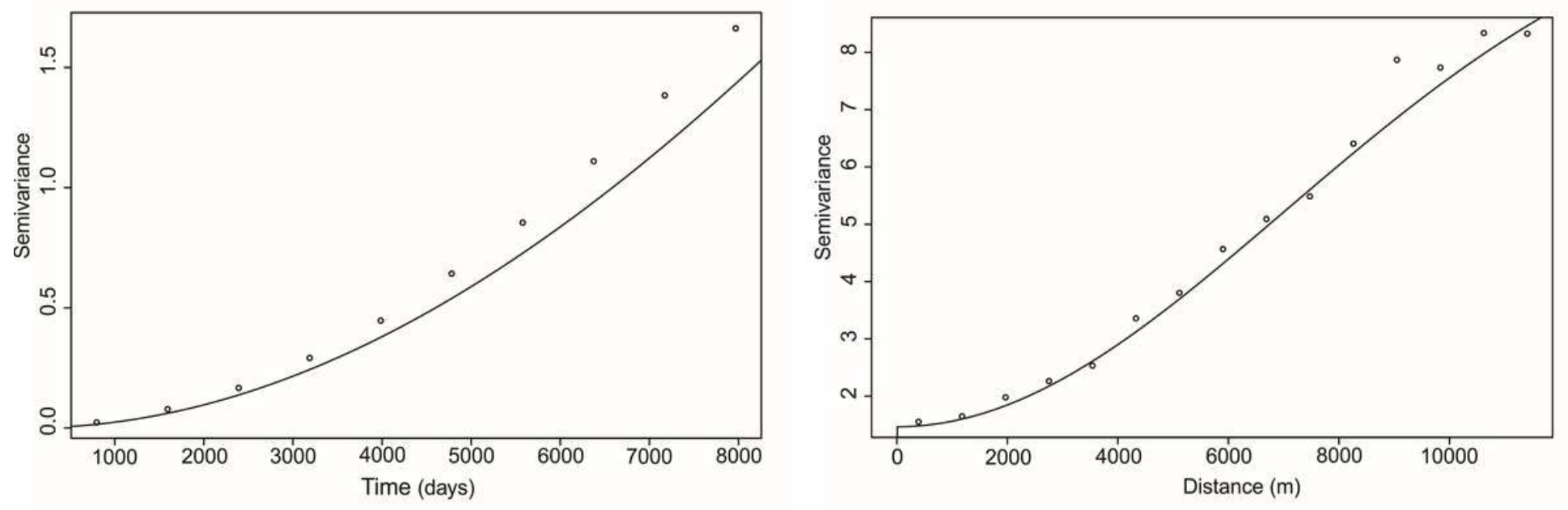

Figure 10

Separable model fitted to the empirical marginal temporal T (left) and spatial S (right) semivariograms

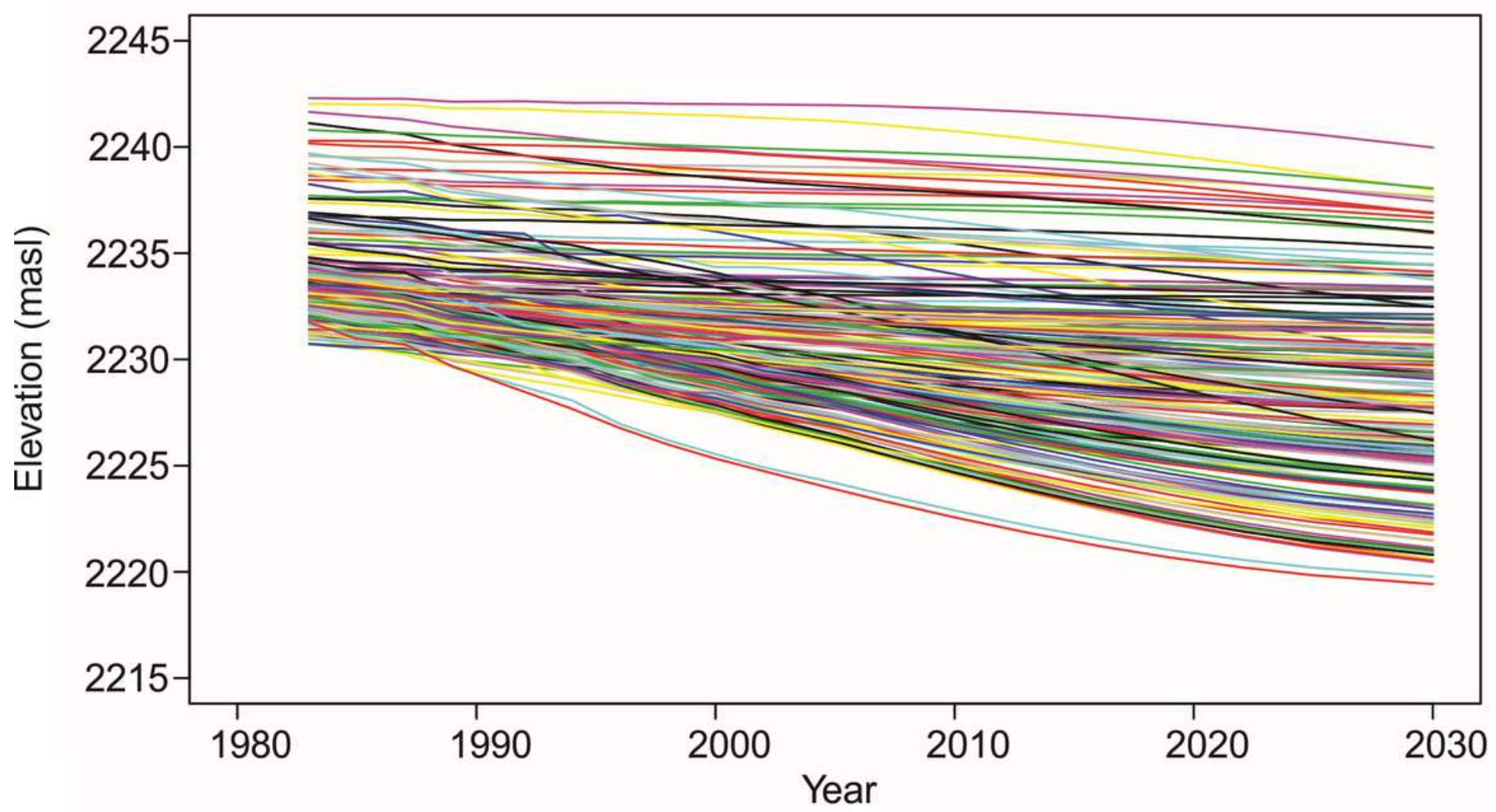

Figure 11

Evolution of the ground elevations during the time period $1983-2030$ at the points where the benchmarks are located 


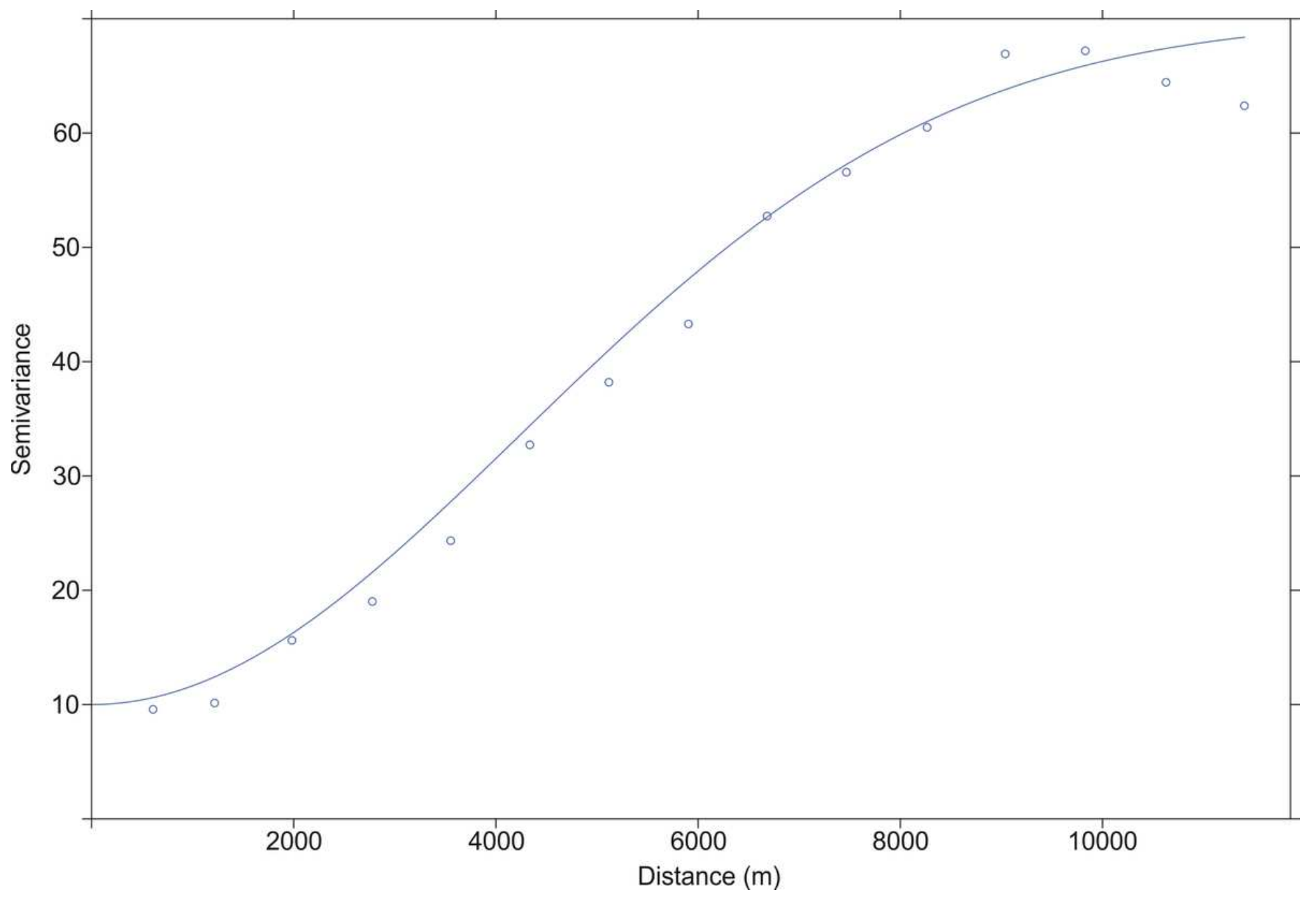

Figure 12

Semivariogram of the predicted mean subsidence rate in the time period $2010-2030$ 展

Figure 13

Mean subsidence rate in the time period 2010-2030 


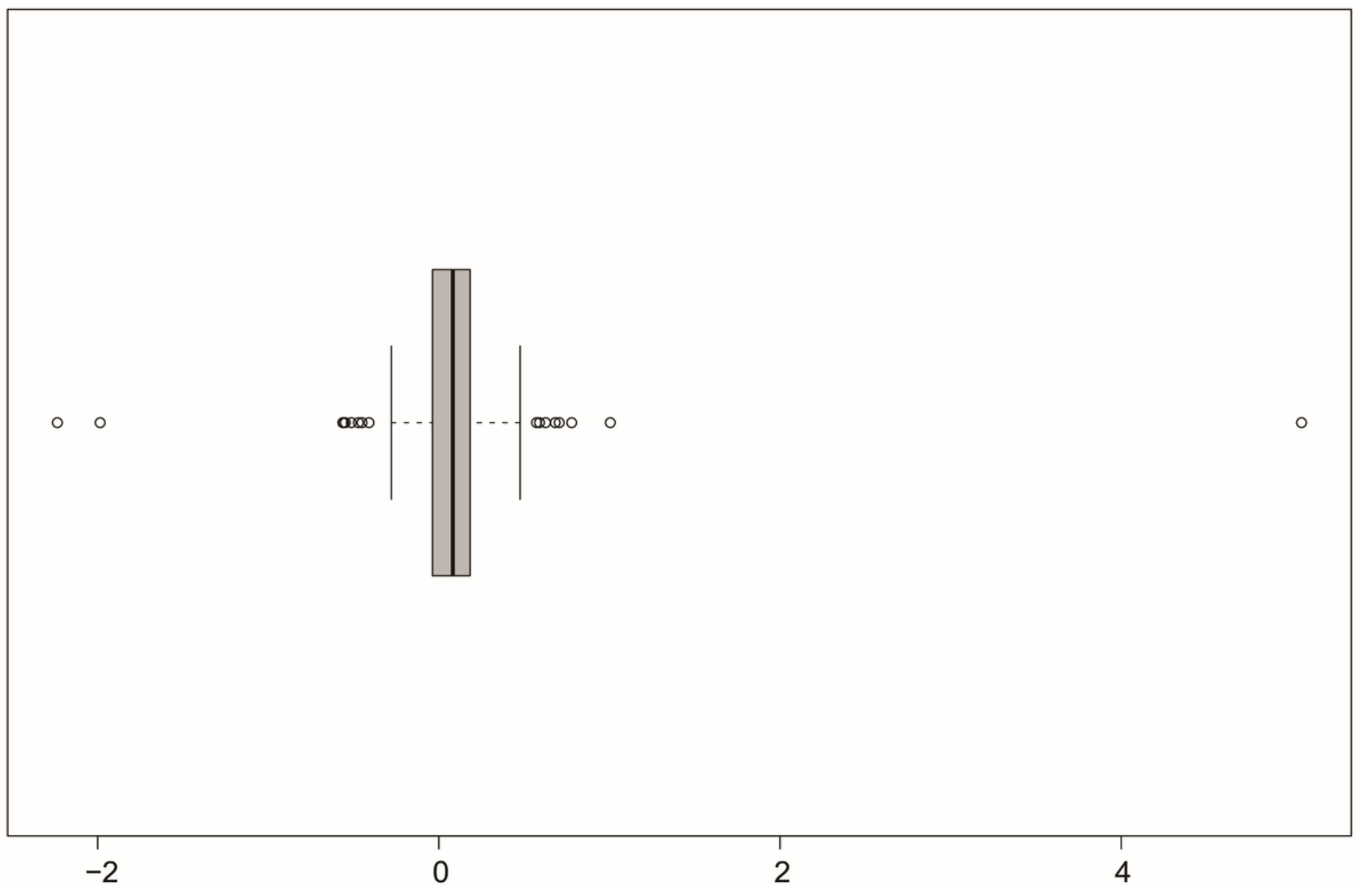

Figure 14

Box-plot of the errors in meters

政

Figure 15

Distribution of the absolute errors in meters 